NBER WORKING PAPER SERIES

\title{
THE EFFECT OF UNCERTAIN LABOR INCOME AND SOCIAL SECURITY ON LIFE-CYCLE PORTFOLIOS
}

\author{
Raimond Maurer \\ Olivia S. Mitchell \\ Ralph Rogalla \\ Working Paper 15682 \\ http://www.nber.org/papers/w15682
}

\author{
NATIONAL BUREAU OF ECONOMIC RESEARCH \\ 1050 Massachusetts Avenue \\ Cambridge, MA 02138 \\ January 2010
}

This research was conducted with support from the Pension Research Council at The Wharton School of the University of Pennsylvania. We are grateful for useful comments from Jason Scott and Ramu Thiagarajan. Opinions and errors are solely those of the authors and not of the institutions with whom the authors are affiliated. This is part of the NBER Program on the Economics of Aging. The views expressed herein are those of the authors and do not necessarily reflect the views of the National Bureau of Economic Research.

NBER working papers are circulated for discussion and comment purposes. They have not been peerreviewed or been subject to the review by the NBER Board of Directors that accompanies official NBER publications.

(C) 2010 by Raimond Maurer, Olivia S. Mitchell, and Ralph Rogalla. All rights reserved. Short sections of text, not to exceed two paragraphs, may be quoted without explicit permission provided that full credit, including $\odot$ notice, is given to the source. 
The Effect of Uncertain Labor Income and Social Security on Life-cycle Portfolios

Raimond Maurer, Olivia S. Mitchell, and Ralph Rogalla

NBER Working Paper No. 15682

January 2010

JEL No. G11,G22,G23,H55,J14,J24,J26

\begin{abstract}
This paper examines how labor income volatility and social security benefits can influence lifecycle household portfolios. We examine how much the individual optimally saves and where, taking into account liquid financial wealth and annuities, and stocks as well as bonds. Higher labor income uncertainty and lower old-age benefits boost demand for stable income in retirement, but also when young. In addition, a declining equity glide path with age is appropriate for the worker with low income uncertainty; for the high income risk worker, equity exposure rises until retirement. We also evaluate how differences in social security benefits can influence retirement risk management.
\end{abstract}

Raimond Maurer

Finance Department, Goethe University

Grüneburgplatz 1 (Uni-PF. H 23)

Frankfurt am Main, Germany

rmaurer@wiwi.uni-frankfurt.de

Olivia S. Mitchell

University of Pennsylvania

Wharton School

3620 Locust Walk, St 3000 SH-DH

Philadelphia, PA 19104-6302

and NBER

mitchelo@wharton.upenn.edu
Ralph Rogalla

Goethe University of Frankfurt

House of Finance (Uni-PF H 23), Gr

D-60323 Frankfurt am Main

rogalla@wiwi.uni-frankfurt.de 


\section{The Effect of Uncertain Labor Income and Social Security on Life-cycle Portfolios}

Risky labor income and pension payouts are key determinants of retirement wellbeing and investment behavior over the life-cycle. In the past, defined benefit (DB) pension plans and social security benefits provided a substantial and relatively stable component of retirement wealth, whereas more recently, labor market flexibility has grown, along with defined contribution (DC) plans. As a result, households will be required to take on increased responsibility for retirement accumulation and decumulation in a more uncertain world. This paper examines how consumers can optimally allocate their saving among two major asset classes, namely equity and bonds, and two types of retirement assets, namely liquid saving and illiquid annuities. We illustrate how incorporating labor income risk as well as social security benefits influences optimal asset allocation, in a realistically-calibrated dynamic lifecycle model.

Our study extends prior literature by taking into account life annuities which pay a defined stream of benefits over the remaining lifetime (e.g. Cocco, Gomes, and Maenhout 2005). This work evaluates the impact of alternative empirical labor income trajectories, allowing for an observed inverted-U-shaped age-related pay profile as well as volatility around that profile. We use this approach to assess how differences in earnings profiles and shocks may drive life-cycle investment behavior and the demand for annuities. We also build on our own prior work (Horneff, Maurer, Mitchell, and Stamos 2009a, b) which shows that households can benefit substantially from holding annuities as well as capital market assets. As demonstrated there, the particular appeal of annuities is that they offer consumers not only an investment return from the underlying assets but also the survival credit generated from pooling mortality risk. ${ }^{1}$ These papers provide insight into how a reasonable investor would

\footnotetext{
${ }^{1}$ For additional references to the rapidly-growing literature on realistically calibrated discrete
} 
optimally save and invest her wealth across bonds, stocks, and annuities, taking into account various levels of social security replacement rates.

In what follows, we model the effect of uncertain labor income and social security benefit replacement ratios on life-cycle portfolios. After outlining the empirical framework employed, we present results on optimal expected consumption, saving, asset allocation, and annuity purchases for representative households. We show that higher labor income risk and lower social security replacement rates will induce higher demand for stable income - not only in retirement but also earlier in life. In other words, individuals exposed to labor earnings risk can, to some extent, "roll their own” personal defined benefit scheme by resorting to the private annuity market. We also show that a declining equity glide path with age is appropriate for both low and middle income risk workers, while, for the high income risk worker, equity exposure rises until retirement.

\section{Empirical Strategy}

To illustrate how different levels of labor income uncertainty and social security retirement benefits affect outcomes of interest, we examine the case of an individual who is assumed to work from the age of 20 until retirement at age 65, after which she expects to rely on social security benefits, withdrawals from liquid saving, and privately-purchased life annuity income. ${ }^{2}$ The maximum assumed survival age is 100 . She can invest her liquid saving in riskless bonds or risky stocks, and she may also purchase immediate real fixed payout

dynamic portfolio choice models, see Horneff, Maurer, Mitchell, and Stamos (2009a, b) and Wachter and Yogo (2009).

${ }^{2}$ For a more detailed description of the modeling approach see Horneff, Maurer, Mitchell, and Stamos (2009a, b); flexible hours and endogenous retirement ages are considered in Chai, Horneff, Maurer, and Mitchell (2009). 
annuities, both before and after retirement. The individual anticipates surviving from period $t$ to $t+1$ with probability $p_{t}^{s}$, which is her subjective probability. She derives CRRA utility from consumption of a single non-durable good C. The value function is maximized over the arguments $C_{t}, \pi_{t}$, and $a_{t}$ according to $V_{t}=\frac{C_{t}^{1-\rho}}{1-\rho}+\beta p_{t}^{s} E_{t}\left[V_{t+1}\right]$ where $\rho$ is the coefficient of relative risk aversion, $\beta$ is a time discount factor, $\pi_{\mathrm{t}}$ is the share of liquid assets held in equities, and $a_{t}$ refers to annuity purchases each period. ${ }^{3}$ The household is precluded from borrowing against future labor income and from short-selling bonds, stocks, and life annuities.

A topic of considerable recent interest is how to model labor income uncertainty. ${ }^{4}$ We posit that each period's labor income $Y_{t}$ is given by $Y_{t}=\exp (f(t)) P_{t} U_{t}$ with $P_{t}=P_{t-1} N_{t}$, where $f(t)$ represents a hump-shaped income profile over the life-cycle often used in empirical research (Cocco, Gomes, and Maenhout 2005). Here, $P_{t}$ represents the permanent human capital component and $N_{t}$ allows for stochastic changes; $U_{t}$ is a transitory shock; $\sigma_{u}$ is the volatility of the transitory shock and $\sigma_{n}$ of the permanent shock. ${ }^{5}$ In retirement $(t>K)$, we assume (for simplicity) that the individual receives constant and real social security benefits with a constant benefit replacement ratio $(\zeta)$ with respect to final salary, expressed as $Y_{t}=\zeta \exp (f(K)) P_{K}$, where $K$ is the final year of work.

\footnotetext{
${ }^{3}$ For this analysis, we assume that the household derives no utility from bequests. Hurd (1989) suggests that most bequests are accidental.

${ }^{4}$ Notable prior studies on asset allocation that consider uninsurable labor income risk include Campbell and Viceira (2002); Heaton and Lucas (1997); Viceira (2001); Bodie, Detemple, Otruba, and Walter (2004); and Polkovnichenko (2007).

${ }^{5}$ The logarithms of both $N_{t}$ and $U_{t}$ are normally distributed with means zero and with volatilities $\sigma_{\mathrm{n}}$ and $\sigma_{\mathrm{u}}$, respectively. The shocks are assumed to be uncorrelated.
} 
Our benchmark case for an illustrative consumer sets preference parameters to standard values found in the life-cycle literature: the relative risk aversion coefficient is $\rho=5$ and the discount factor $\beta=0.96$ (e.g. Gomes and Michaelides, 2005). Representing subjective survival probabilities, we apply nonlinear least squares to fit the Gompertz force of mortality to the 2000 Population Basic mortality table for US females. To calculate the actuarial premium of a life payout annuity, we use annuitant mortality tables and include expense loading $\lambda$ of 7.2 percent, consistent with Mitchell et al. (1999). The household can directly invest in two financial assets: riskless bonds and risky stocks. The riskless real bond gross return is 2 percent, while the real risky stock return is log-normally distributed with an expected return of 6 percent and a volatility of 18 percent as in much of the literature. The deterministic age-dependent labor income function for an individual with only a high-school education is taken from Cocco, Gomes, and Maenhout (2005). The assumed base case social security replacement rate $\zeta$ of 68 percent is currently typical of low-wage retirees in the United States (Mitchell and Phillips 2006). In an alternative scenario, we also show how outcomes would change with a lower replacement rate of 50 percent; this figure is consistent with replacement ratios for low-wage earners in Japan (OECD 2009: 39). These two alternatives are of interest given that Japan's current demographic situation and social security shortfalls may well presage the future for the United States.

The labor income volatility parameters for the base case are $\sigma_{n}=0.05$ and $\sigma_{u}=0.075$, representing a labor income profile with relatively low risk; here correlations between the stock returns and the permanent (transitory) income shocks are set to $\phi_{n}=0\left(\phi_{u}=0\right)$. In the alternative scenario, we evaluate results using a much higher labor income risk volatility of four times the base level as well as $\phi_{n}=0.25$. In sensitivity analysis, we also show results for 
lower $(\rho=3)$ and higher $(\rho=8)$ levels of risk aversion. ${ }^{6}$ Table 1 summarizes model parameters.

Table 1 here

\section{Life-cycle Patterns of Investment, Saving, and Consumption}

The base case investor is one with low labor income risk, high social security replacement rate, and medium risk aversion, who faces incomplete private markets for immediate annuities with high loadings. Results appear in Figure 1, which displays the expected development of labor income, consumption, liquid saving, annuity purchases, and annuity income from age 20 to 100 . To generate a smooth lifetime consumption path, the worker saves from her 30’s to her mid-50's so as to pay for later consumption. By her late 50’s, liquid assets - outside of annuities - rise to a maximum of almost 11 times her starting or initial labor income. After that, the investor gradually starts drawing down assets to compensate for declining labor income; after about age 60, liquid assets are deployed to buy private annuities. From retirement at age 65, liquid assets are depleted rapidly permitting the retiree to maintain pre-retirement consumption; as well, she relies increasingly on income flowing from private annuities, which she continues to buy even well beyond retirement age. In her early 80s, her liquid assets are fully exhausted because she has no bequest motive; after that point, the annuity payout stream is considerable, helping maintain a smooth consumption path throughout her remaining lifetime.

\footnotetext{
${ }^{6}$ We solve the optimization problem by backward induction in a three-dimensional state space, whereby for each grid point we evaluate the policy and value functions using Gaussian quadrature integration and cubic spline interpolation. For technical details we refer the interested reader to Horneff, Maurer, and Stamos (2008) and Horneff, Maurer, Mitchell, and Stamos (2009a, b).
} 
Figure 1 here

Figure 2 indicates how liquid assets as a multiple of first-year labor income, and saving rates are expected to change with age. The saving rate is defined as SRate $_{t}=1-C_{t} /$ Income $_{t}$ and Income refers to the flow of labor income and annuity benefits. ${ }^{7}$ The base case is represented by the solid line, for the low labor income risk/high social security replacement rate scenario. In this safer world, the individual has little need to save early in life: the saving rate is low at young ages and only from the mid-20's does saving rise, with a peak in the mid-40's of 10 percent per year, and it becomes negative ( -5 percent) in the mid-50’s. After retirement, saving rates drop precitipitously and reach a negative -40 percent so as to smooth consumption; the elderly older than about age 85 have a saving rate of zero. Liquid assets grow slowly early in life, rising to around 10 times first-year labor income at their peak.

Figure 2 here

In the riskier scenario, the social security replacement rate is reduced to 50 percent, and labor income risk is four times the base level and correlated with the stock market. Here, the young adult will engage in substantially higher saving to build a buffer against high labor income volatility - over 40 percent per annum. Assets rise to 40 times first-year income by the late 50 `s. Next, the saving rate falls, crossing the zero mark around the early 60's; thereafter it rises again briefly just before retirement to offset low social security benefits. As we shall show next, the money is used mainly to purchase annuities that provide a secondary stable income stream in retirement. Nevertheless, this individual's liquid saving continues to rise

\footnotetext{
${ }^{7}$ Here we report the saving rate as SRate $_{t}=1-E\left(C_{t}\right) / E\left(\right.$ Income $\left._{t}\right)$; in unreported results, we have also computed SRate $_{t}=1-E\left(C_{t} /\right.$ Income $\left._{t}\right)$ which is substantially lower in the high risk/low replacement rate scenario.
} 
through the mid-50's, due to returns on investment. After retirement, at 65, when the social security benefit begins, assets are consumed and the saving rate trajectory follows the one described earlier.

Turning to Figure 3, the three Panels illustrate how the individual will optimally allocate her total financial wealth by age across equities, bonds, and private annuities; here, total financial wealth is defined to include both liquid assets and the present value of future private annuity income claims. On average, as is indicated in Panel A, the base case individual (solid line) will optimally hold only equities from youth to about age 50 (apart from a few bonds early on, shown in Panel B). This is a common result in many life-cycle studies and occurs because, early in life, the individual's main asset is human capital which has bond-like payout characteristics. This is especially true with low labor income uncertainty, where her relatively safe labor income is also protected in retirement with a relatively high social security benefit. She will optimally diversify her complete portfolio, which includes both the present value of her human capital (labor income plus social security benefits) as well as financial assets, by holding little to nothing in bonds and instead invests entirely in equities. Beginning about age 55, her asset allocation begins to include more bonds as her remaining work years dwindle.

The optimal pattern for privately-purchased annuities is illustrated in Panel C; these play no role in the investor's portfolio prior to the age of 59, as they are relatively unattractive vis $a$ vis bonds due to high loading and the use of annuitant survival tables in pricing. At older ages, however, the annuity survival credit rises above the bond rate; as a result, annuities crowd out bonds. In retirement, liquid assets are depleted to support consumption and buy annuities, which provide a secure private income stream (assuming no bequests). From the early 80 ’s, the retiree is fully annuitized. 
These results should be contrasted those generated by the alternative scenario with high labor income uncertainty and low social security replacement rates. ${ }^{8}$ In general we would expect that this consumer will need to save more, and hold more safe assets. This is borne out in Panels A-C (dashed line), where the equity fraction starts at zero and even in middle age remains below 30 percent; by contrast the bond fraction starts out at 100 percent and falls as the worker nears retirement. This is because labor income no longer produces a bond-like stream of payments that previously pushed the young investor into equities. This investor also demands more annuities, beginning around age 45, to help offset variable work earnings. The annuitized fraction then rises quickly around retirement, to help offset the now-low social security replacement rates. Around age 60, the rising survival credit dominates the annuity pricing offsets due to loads and the use of annuitant mortality tables. In all cases the transition to annuities is accomplished by a substantial movement out of bonds: her allocation to bonds drops from 65 to about 15 percent. As in the base case, the individual is fully annuitized from age 83 onward. It is also worth noting that, around age 65 when she becomes entitled to social security benefits, she is no longer exposed to labor income risk. Accordingly, the stabile private annuity income plus the social security payments permits the investor to hold more equities. Thus equity exposure rises to over 40 percent, and then it gradually declines in favor of annuities, until liquid savings are exhausted at age $83 .^{9}$

\section{Sensitivity Analysis}

\footnotetext{
${ }^{8}$ These are partial equilibrium computations, in that lower social security benefit are not offset by social security tax cuts.

${ }^{9}$ This is because of the increasing survival credit at older ages, which raises expected annuity payouts vis a vis equities (Horneff, Maurer, Mitchell, and Stamos 2009a, b).
} 
Next we review how results change across six combinations of labor income risk levels and social security replacement rates; comparative results appear in Table 2. Panel A focuses on the high social security replacement rate scenario and reports liquid assets, saving rates, and asset allocation fractions, for three workers: the low income volatility case (the base case above), a high volatility case (the alternative scenario defined above), and a middle risk case (defined as $\sigma_{n}=0.10, \sigma_{u}=0.20$ and $\phi_{n}=0$ ). Panel B indicates the same results for a lower social security benefit replacement rate of 50 percent. We report patterns for five decades of life from age 45 to 85 .

Table 2 here

Comparing Panels A and B for all three levels of labor income risk, it is evident that the Panel B individual (with lower old-age benefits) accumulates more liquid assets (row 6 vs row 1 ) by saving more early in life (row 7 vs row 2) but she draws down her assets more quickly after retirement, so as to preserve her consumption stream. Now, moving horizontally across the table, irrespective of social security benefit levels, as labor income risk rises, so too do liquid assets. For example, even by age 45, the high labor income risk individual has amassed assets five times more due to a much higher saving rate (17.4 percent vs 8.5 percent). ${ }^{10}$

Moving horizontally across the table, it is clear that more labor income risk reduces the demand for equities (rows 3 and 8), irrespective of the social security replacement rate. Similarly, higher income risk makes annuities more attractive at younger ages, in all cases (rows 5 and 10). As seen above, a declining equity glide path with age is appropriate for both

\footnotetext{
${ }^{10}$ In the medium labor income case, the saving rate is always lower than for the low income risk case, though liquid assets are higher in all cases. This is due to the fact that this medium income risk individual saves from a younger age, and at a higher rate (in results available on request).
} 
low and middle income risk workers, while, for the high income risk worker, equity exposure optimally rises until retirement. Moving down the table, we note that lower replacement rates prompt lower equity holdings for both low and middle income risk workers, while bonds and annuities become more desirable. For those facing high labor income risk, asset allocation patterns are less sensitive to old-age benefit levels, though the direction is similar.

Next we investigate the sensitivity of our results with respect to the investor's level of risk aversion. In addition to the base case risk parameter $(\gamma=5)$ analyzed above, Table 3 tabulates results for low $(\gamma=3)$ and high $(\gamma=8)$ relative risk aversion levels, assuming the worker has a medium labor income volatility (so she is exposed to risk other than through the capital market). As before, Panel A presents patterns of liquid saving and saving rates, as well as allocations to equities, bonds, and annuities for the high social security replacement rate; Panel B provides results for the lower value.

\section{Table 3 here}

Here, as risk aversion rises (moving horizontally across the table), liquid assets and expected saving rates again rise (rows 1, 2, 6, and 7), irrespective of the social security replacement rate; that is, higher risk aversion enhances the appeal of saving. Moving down the table, when social security benefits are reduced at a given level of labor uncertainty, higher saving rates and liquid assets are observed at younger, but not at older, ages. Also, as we move to the right in the table, as risk aversion rises, it is evident and unsurprising that the fraction in equities falls in favor of bonds and annuities. Going down a column, when the replacement rate drops, again the equity fraction falls - though it is interesting that at age 85, the least risk averse consumer still holds 15 percent of her portfolio in equities. In all three cases, bonds dominate at younger ages, while annuities crowd out bonds at older ages.

\section{Conclusions}


Retirement risk management is likely to become increasingly important with global demographic aging, a phenomenon already requiring social security benefit cuts in some developed nations such as Japan. This paper illustrates how increasing labor income risk and reductions in social security replacement rates could influence saving, life-cycle portfolio asset demand, and purchases of payout annuities. Our model shows that higher labor income risk and lower social security replacement rates boost saving rates early in life and liquid assets accumulated for precautionary purposes. A more uncertain and less generous environment also induces greater demand for protection in the form of stable income - early in life and in retirement. The enhanced need for safety is met not only with bonds, but also with payout annuities whereas the demand for equities falls. Also, individuals who are more risk averse save more early in life, and hold fewer equities.

Our analysis offers several useful implications. For instance, financial advisers might seek to consider possible future social security benefit cuts as they design optimal lifetime asset accumulation paths and portfolio allocations for younger clients. Also, the financial services industry and pension sponsors would benefit by taking careful account of labor income risk when formulating recommendations for client portfolios. Thus in the context of our model, low and middle income risk workers will favor an equity glide path which declines with age, but for those facing high income risk, equity exposure would optimally be low early in life and rise until retirement. Moreover, for those with uncertain labor income, it would be desirable to purchase immediate payout annuities early in life so as to build up a second more stable stream of income. Our work underscores the need for workers to have a way to create their own defined benefit plan equivalents with privately purchased payout annuities. 


\section{References}

Bodie, Zvi, Jérôme B. Detemple, Susanne Otruba, and Stephan Walter. (2004). 'Optimal Consumption-Portfolio Choices and Retirement Planning.' Journal of Economic Dynamics and Control, 28: 1115-1148.

Campbell, John and Luis Viceira. (2002). 'Strategic Asset Allocation: Portfolio Choice for Long-Term Investors.' Clarendon Lectures in Economics. Oxford: Oxford University Press.

Chai, Jingjing, Wolfram Horneff, Raimond Maurer, and Olivia S. Mitchell. (2009). 'Extending Life Cycle Models of Optimal Portfolio Choice: Integrating Flexible Work, Endogenous Retirement, and Investment Decisions with Lifetime Payouts.' NBER WP 15079.

Cocco, João, Francisco Gomes, and Pascal Maenhout. (2005). 'Consumption and Portfolio Choice over the Life Cycle.’ Review of Financial Studies, 18: 491-533.

Gomes, Francisco and Alexander Michaelides. (2005). 'Optimal Life-Cycle Asset Allocation: Understanding the Empirical Evidence.’ Journal of Finance, 60: 869-904.

Heaton, John and Deborah Lucas. (1997). 'Market Frictions, Savings and Portfolio Choice.' Macroeconomic Dynamics, 1: 76-101.

Horneff, Wolfram, Raimond Maurer, Olivia S. Mitchell, and Michael Stamos. (2009a). ‘Asset Allocation and Location Over the Life Cycle with Survival Contingent Payouts.' Journal of Banking and Finance. 33: 1688-1699.

Horneff, Wolfram, Raimond Maurer, Olivia S. Mitchell, and Michael Stamos. (2009b). 'Variable Payout Annuities and Dynamic Portfolio Choice in Retirement.' Journal of Pension Economics and Finance. Forthcoming. 
Horneff, Wolfram, Raimond Maurer, and Michael Stamos. (2008). 'Life-Cycle Asset Allocation with Annuity Markets.' Journal of Economic Dynamics and Control, 32: 3590-3612.

Hurd, Michael. (1989). 'Mortality Risk and Bequests.’ Econometrica, 57: 779-813. Mitchell, Olivia S. and John Phillips. (2006). 'Social Security Replacement Rates For Alternative Earnings Benchmarks.’ Benefits Quarterly, 4th Q: 37-47.

Mitchell, Olivia S., James Poterba, Mark Warshawsky, and Jeffrey Brown. (1999). 'New Evidence on the Money Worth of Individual Annuities.' American Economic Review, 89: $1299-1318$.

OECD. (2009). 'Pensions at a Glance: 2009, Retirement Income Systems in OECD Countries.’ OECD: Paris.

Polkovnichenko, Valery. (2007). 'Life-Cycle Portfolio Choice with Additive Habit Formation Preferences and Uninsurable Labor Income Risk.’ Review of Financial Studies, 20: 83-124.

Viceira, Luis. (2001). 'Optimal Portfolio Choice for Long-Horizon Investors with Nontradable Labor Income.’ Journal of Finance, 56: 433-470.

Wachter, Jessica and Motohiro Yogo. (2009). 'Why Do Household Portfolio Shares Rise in Wealth?' Working Paper presented at the AFA 2008 New Orleans Meetings. 
Figure 1: Life-cycle Asset Allocation Patterns: Low Labor Income Risk and High Social Security Replacement Rate

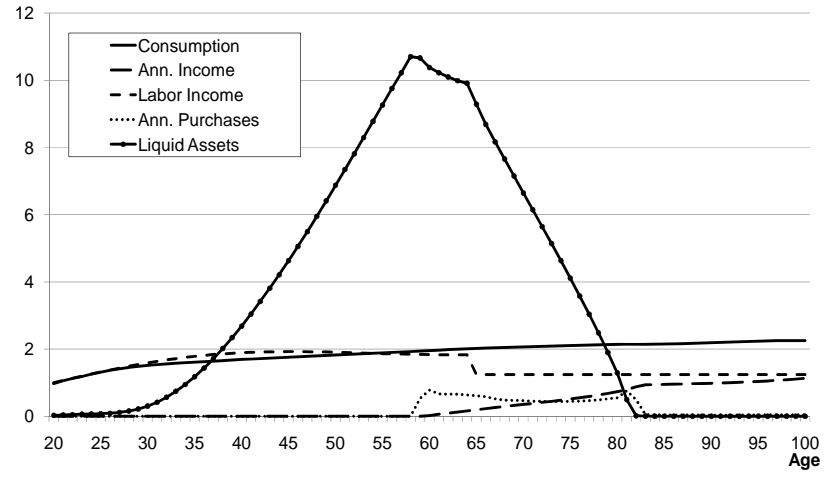

Source: Authors' calculations. Notes: The Figure embodies a retirement age of 65; replacement rate of 68\%; annuity loading of 7.2\%; moderate risk aversion $(\rho=5)$; volatility of transitory income shock $=7.5 \%$; volatility of permanent income shock $=5 \%$; and correlation of permanent labor income shock with equity returns $=0$ (see text). Labor income, consumption, liquid assets, annuity purchases, and annuity payouts, are expressed as a multiple of first-year labor income. 
Figure 2: Liquid Assets and Saving Rates for Low vs High Labor Income Risk Levels and High vs Low Social Security Replacement Rates

(A) Liquid Assets

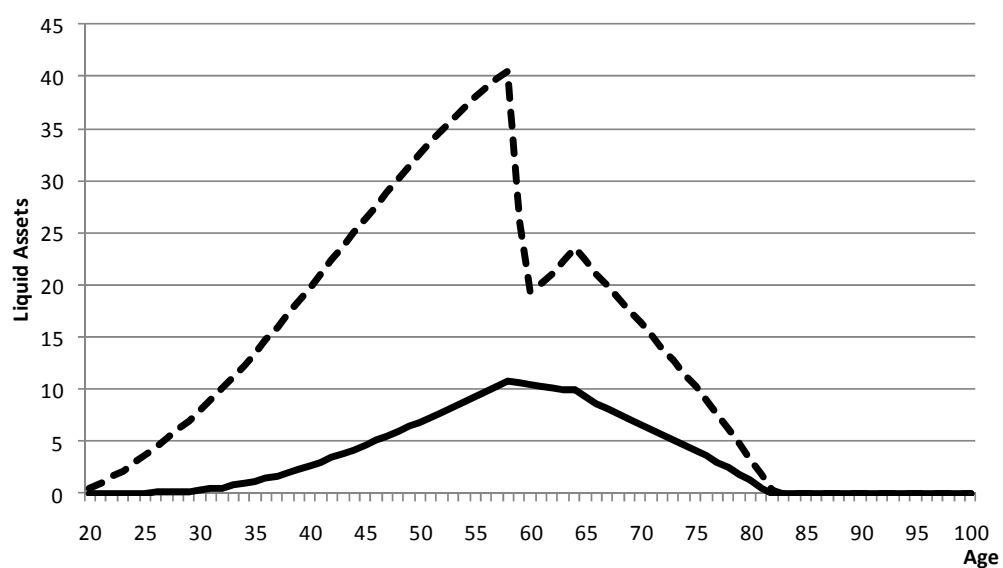

(B) Saving Rates

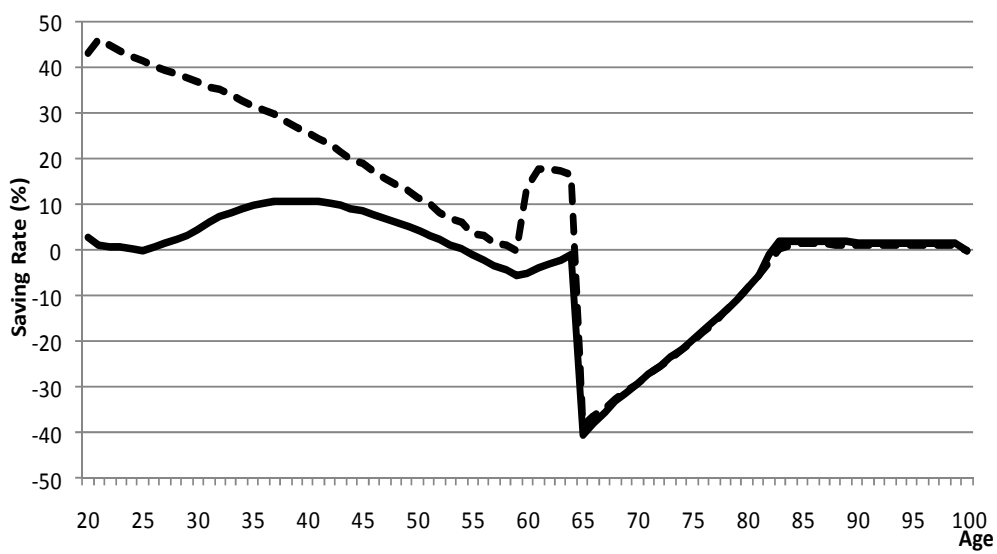

Low Labor Income Risk, High Social Security Replacement Rate (68\%)

- . - . High Labor Income Risk, Low Social Security Replacement Rate (50\%)

Source: Authors' calculations. Notes: Liquid asset (held in stocks and bonds) are expressed a multiple of first-year labor income; saving rates are the percent of labor plus annuity income saved. 
Figure 3: Life-cycle Asset Allocation for Low vs High Labor Income Risk Levels and High vs Low Social Security Replacement Rates

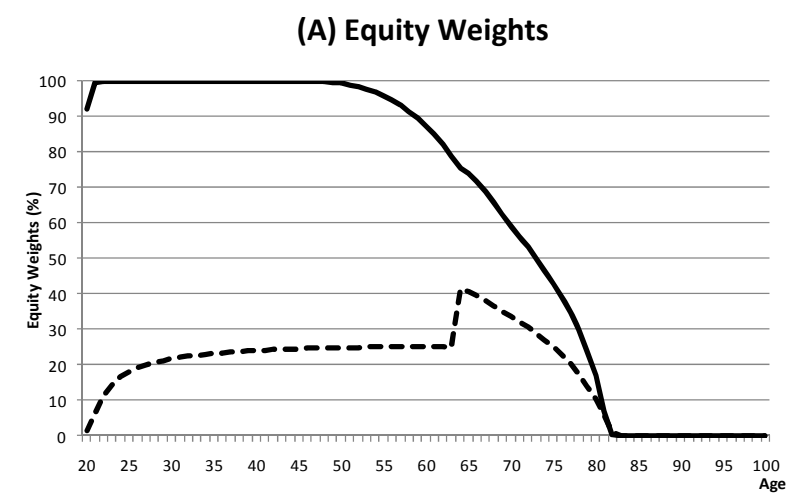

(B) Bond Weights

(C) Annuity Weights
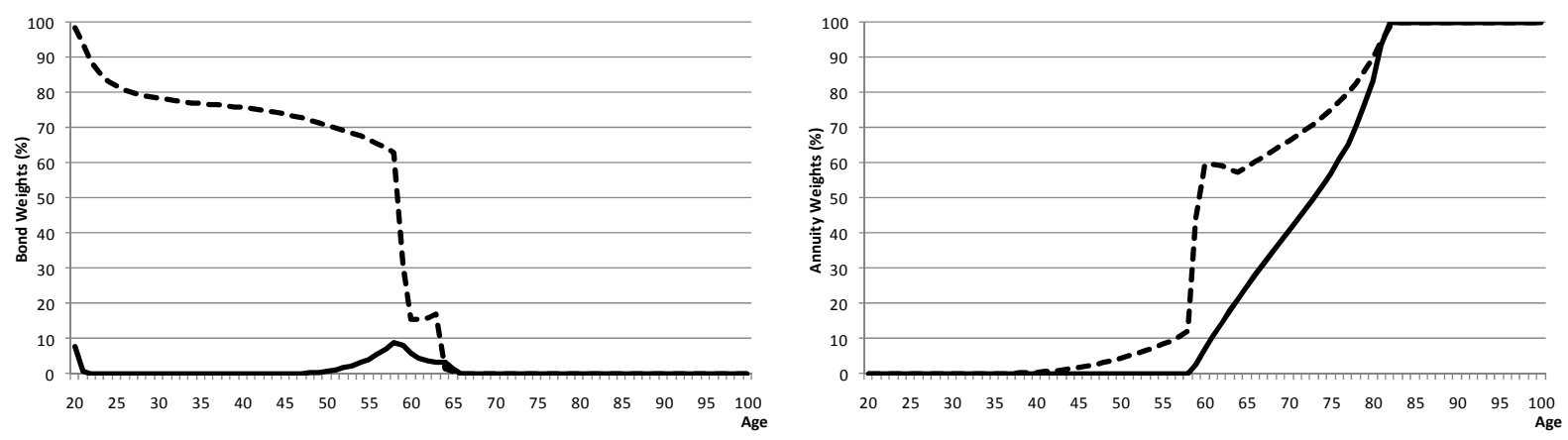

Low Labor Income Risk, High Social Security Replacement Rate (68\%)

- - - - - High Labor Income Risk, Low Social Security Replacement Rate (50\%)

Source: Authors' calculations. Notes: Asset weights expressed as a percent of total wealth (liquid assets + present value of annuity claims). 
Table 1: Behavioral and Market Parameters Employed in Empirical Analysis

\begin{tabular}{lccccc}
\hline & $\sigma_{\mathrm{n}}$ & $\sigma_{\mathrm{u}}$ & $\phi_{\mathrm{n}}$ & $\zeta$ & $\rho$ \\
\cline { 2 - 6 } Low & 0.05 & 0.075 & 0.00 & 0.50 & 3 \\
Med & 0.10 & 0.200 & 0.00 & 0.60 & 5 \\
High & 0.20 & 0.300 & 0.25 & 0.68 & 8 \\
\hline
\end{tabular}

Source: Authors' compilation.

Notes: $\sigma_{\mathrm{n}}$ and $\sigma_{\mathrm{u}}$ refer respectively to the volatility of the permanent and transitory income shocks; $\phi_{n}$ is the correlation of labor income risk with stock returns; $\zeta$ is the social security replacement rate; and $\rho$ is the coefficient of relative risk aversion coefficient. 
Table 2: Life-cycle Saving Rates and Portfolio Mixes for Alternative Labor Income Risk Levels and Social Security Replacement Rates

\begin{tabular}{|c|c|c|c|c|c|c|c|c|c|}
\hline \multicolumn{5}{|c|}{ Low Labor Income Risk } & \multicolumn{5}{|c|}{ Medium Labor Income Risk } \\
\hline & & Age & & & & & Age & & \\
\hline 45 & 55 & 65 & 75 & 85 & 45 & 55 & 65 & 75 & 85 \\
\hline (1) & (2) & (3) & (4) & (5) & (6) & (7) & (8) & (9) & (10) \\
\hline
\end{tabular}

\begin{tabular}{ccccc}
\multicolumn{5}{c}{ High Labor Income Risk } \\
\hline \multicolumn{5}{c}{ Age } \\
45 & 55 & 65 & 75 & 85 \\
\hline$(12)$ & $(13)$ & $(14)$ & $(15)$ & $(16)$ \\
\hline
\end{tabular}

Panel A: High Social Security Replacement Rate (68\%)

$\begin{array}{lcccccc}\text { Liquid Assets } & (1) & 4.6 & 9.3 & 9.3 & 4.1 & 0.0 \\ \text { Saving Rate (\%) } & (2) & 8.5 & -1.2 & -40.4 & -19.8 & 1.9 \\ \text { Equities (\%) } & (3) & 100.0 & 95.8 & 74.0 & 43.1 & 0.0 \\ \text { Bonds (\%) } & (4) & 0.0 & 4.2 & 1.3 & 0.0 & 0.0 \\ \text { Annuities (\%) } & (5) & 0.0 & 0.0 & 24.7 & 56.9 & 100.0\end{array}$

$\begin{array}{ccccc}11.1 & 17.9 & 12.9 & 5.7 & 0.0 \\ 5.9 & -11.0 & -41.5 & -20.0 & 1.8 \\ 92.8 & 75.6 & 59.3 & 34.9 & 0.0 \\ 7.2 & 24.3 & 1.3 & 0.0 & 0.0 \\ 0.0 & 0.1 & 39.4 & 65.1 & 100.0\end{array}$

$\begin{array}{ccccc}25.7 & 36.3 & 23.6 & 11.1 & 0.0 \\ 17.4 & -0.1 & -35.8 & -19.7 & 1.8 \\ 24.4 & 24.8 & 47.3 & 29.6 & 0.0 \\ 74.0 & 67.3 & 0.8 & 0.0 & 0.0 \\ 1.6 & 7.9 & 51.9 & 70.4 & 100.0\end{array}$

Panel B: Low Social Security Replacement Rate (50\%)

\begin{tabular}{|c|c|c|c|c|c|c|c|c|c|c|c|c|c|c|c|c|}
\hline & & & & & & & & & & & & & & & & \\
\hline Liquid Assets & (6) & 6.0 & 12.3 & 9.2 & 4.0 & 0.0 & 12.4 & 20.4 & 12.2 & 5.3 & 0.0 & 26.3 & 38.0 & 22.3 & 10.2 & 0.0 \\
\hline Saving Rate (\%) & (7) & 11.4 & 2.3 & -42.9 & -20.1 & 1.4 & 8.4 & -6.6 & -42.6 & -20.1 & 1.4 & 18.9 & 3.8 & -38.3 & -19.9 & 1.3 \\
\hline Equities (\%) & (8) & 99.8 & 86.5 & 52.9 & 31.0 & 0.0 & 88.9 & 66.3 & 46.3 & 27.5 & 0.0 & 24.5 & 25.0 & 40.5 & 25.0 & 0.0 \\
\hline Bonds (\%) & (9) & 0.2 & 13.5 & 1.3 & 0.0 & 0.0 & 11.1 & 33.6 & 1.2 & 0.0 & 0.0 & 73.8 & 66.6 & 0.8 & 0.0 & 0.0 \\
\hline Annuities (\%) & (10) & 0.0 & 0.0 & 45.8 & 69.0 & 100.0 & 0.0 & 0.1 & 52.5 & 72.5 & 100.0 & 1.7 & 8.4 & 58.7 & 75.0 & 100.0 \\
\hline
\end{tabular}

Source: Authors’ calculations. Notes: Model assumes a retirement age of 65; annuity loading of 7.2\%; moderate risk aversion $(\gamma=5)$. For the case of low labor income risk, the volatility of transitory income shock is 7.5\%; of the permanent income shock is $5 \%$ and the correlation of the

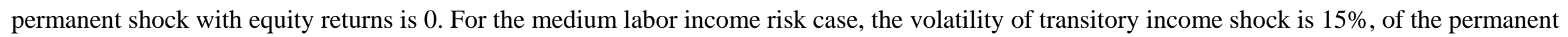

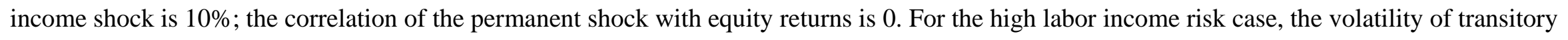
income shock is $30 \%$, of the permanent income shock is $20 \%$; the correlation of the permanent shock with equity returns is 0.25 . Investment

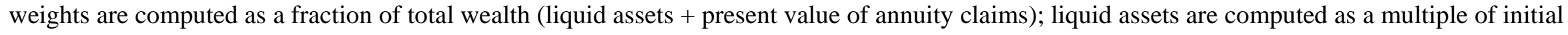
labor income; saving rates are the percent of labor plus annuity income saved. 
Table 3: Life-cycle Saving Rates and Portfolio Mixes for Alternative Levels of Risk Aversion and Social Security Replacement Rates

\begin{tabular}{|c|c|c|c|c|c|c|c|c|c|c|c|c|c|c|}
\hline \multicolumn{5}{|c|}{ Low Risk Aversion $(\gamma=3)$} & \multicolumn{5}{|c|}{ Med. Risk Aversion $(\gamma=5)$} & \multicolumn{5}{|c|}{ High Risk Aversion $(\gamma=8)$} \\
\hline \multicolumn{5}{|c|}{ Age } & \multicolumn{5}{|c|}{ Age } & \multicolumn{5}{|c|}{ Age } \\
\hline 45 & 55 & 65 & 75 & 85 & 45 & 55 & 65 & 75 & 85 & 45 & 55 & 65 & 75 & 85 \\
\hline (1) & (2) & (3) & (4) & (5) & (6) & (7) & (8) & (9) & (10) & (12) & (13) & (14) & (15) & (16) \\
\hline
\end{tabular}

Panel A: High Social Security Replacement Rate (68\%)

\begin{tabular}{|c|c|c|c|c|c|c|c|c|c|c|c|c|c|c|c|c|}
\hline Liquid Assets & (1) & 6.5 & 11.4 & 14.3 & 7.2 & 0.8 & 11.1 & 17.9 & 12.9 & 5.7 & 0.0 & 15.6 & 22.0 & 8.4 & 3.8 & 0.0 \\
\hline Saving Rate (\%) & $(2)$ & 5.7 & -7.4 & -69.8 & -48.3 & -15.6 & 5.9 & -11.0 & -41.5 & -20.0 & 1.8 & 7.8 & -10.9 & -17.8 & -6.0 & 6.2 \\
\hline Equities (\%) & (3) & 100.0 & 99.3 & 94.7 & 74.5 & 29.3 & 92.8 & 75.6 & 59.3 & 34.9 & 0.0 & 49.3 & 39.2 & 32.6 & 19.3 & 0.0 \\
\hline Bonds (\%) & (4) & 0.0 & 0.6 & 0.4 & 0.0 & 0.0 & 7.2 & 24.3 & 1.3 & 0.0 & 0.0 & 50.7 & 60.7 & 0.5 & 0.0 & 0.0 \\
\hline Annuities (\%) & (5) & 0.0 & 0.0 & 4.9 & 25.5 & 70.7 & 0.0 & 0.1 & 39.4 & 65.1 & 100.0 & 0.0 & 0.1 & 66.9 & 80.7 & 100.0 \\
\hline \multicolumn{17}{|c|}{ Panel B: Low Social Security Replacement Rate (50\%) } \\
\hline Liquid Assets & $(6)$ & 7.6 & 14.2 & 16.9 & 7.6 & 0.8 & 12.4 & 20.4 & 12.2 & 5.3 & 0.0 & 16.4 & 23.8 & 7.9 & 3.5 & 0.0 \\
\hline Saving Rate (\%) & (7) & 8.0 & -4.0 & -98.2 & -54.1 & -16.2 & 8.4 & -6.6 & -42.6 & -20.1 & 1.4 & 10.2 & -6.2 & -18.2 & -6.0 & 6.3 \\
\hline Equities (\%) & (8) & 100.0 & 98.1 & 84.5 & 56.7 & 15.0 & 88.9 & 66.3 & 46.3 & 27.5 & 0.0 & 46.4 & 35.1 & 26.9 & 16.1 & 0.0 \\
\hline Bonds (\%) & (9) & 0.0 & 1.9 & 1.0 & 0.0 & 0.0 & 11.1 & 33.6 & 1.2 & 0.0 & 0.0 & 53.6 & 64.8 & 0.3 & 0.0 & 0.0 \\
\hline Annuities (\%) & (10) & 0.0 & 0.1 & 14.6 & 43.3 & 85.0 & 0.0 & 0.1 & 52.5 & 72.5 & 100.0 & 0.0 & 0.1 & 72.8 & 83.9 & 100.0 \\
\hline
\end{tabular}

Source: Authors' calculations. Notes: Results are computed for the medium labor income risk case; here the volatility of transitory income shock is $15 \%$ and for the permanent income shock $10 \%$; and the correlation of the permanent shock with equity returns is 0 . For other definitions see Table 2. 